\title{
Tratamento da retocolite ulcerativa leve/moderada
}

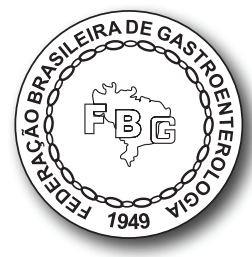

Adérson Omar Mourão Cintra Damião

\section{INTRODUÇÃO}

As doenças inflamatórias intestinais (DII) são caracterizadas por inflamação crônica, de caráter recidivante, que resultam de uma resposta imunológica inapropriada em indivíduos geneticamente suscetíveis, englobando essencialmente duas formas de apresentação: a retocolite ulcerativa (RCU) e a doença de Crohn (DC). A DC caracteriza-se por uma inflamação transmural crônica do tubo digestivo, que pode acometer da boca ao ânus de forma segmentar ou salteada, com frequente comprometimento da região ileal ou ileocecal. A RCU acomete a mucosa (eventualmente a submucosa) dos cólons e reto e, classicamente, apresenta distribuição simétrica, ascendente e contínua $^{1-3}$. Neste capítulo, quando nos referirmos à DII, estaremos falando da RCU e da DC.

Apesar de muitas outras doenças inflamatórias afetarem o trato gastrointestinal, a maioria pode ser distinguida por um agente etiológico específico ou por características específicas. Em contraste, as causas das duas formas mais importantes de DII não estão completamente elucidadas. DC e RCU são definidas pelos seus aspectos clínicos, patológicos, radiológicos, endoscópicos e laboratoriais. Outras causas de inflamação intestinal, como infecções (bacteriana, viral, micobacteriana e amebiana), isquemia, danos iatrogênicos (radiação e drogas) e neoplasias (linfoma), devem ser excluídas ${ }^{4}$. RCU e DC são desencadeadas a partir da interação de fatores genéticos, ambientais, disbiose e alterações na imunorregulação da mucosa intestinal ${ }^{2-5}$. 
A DII pode acometer indivíduos de ambos os sexos em qualquer faixa etária, porém incide predominantemente entre 20 e 40 anos de idade, com forte impacto na qualidade de vida e na atividade social, laboral e econômica. Os fatores étnicos relacionados com a DII são muito controversos, mas parece haver maior incidência em indivíduos caucasianos. A base genética da DII vem sendo muito explorada nos estudos de associação do genoma, os quais ensejaram a identificação de mais de 50 genes de suscetibilidade. A hipótese ambiental mais aceita atualmente diz respeito ao maior consumo de alimentos industrializados, ricos em xenobióticos (p. ex., conservantes, corantes e aditivos) com potente efeito antigênico. De fato, a DII ocorre mais comumente em países industrializados, fato que aponta a urbanização como um fator de risco em potencial, com a ocidentalização do estilo de vida e da dieta, a mudança de hábitos alimentares e o hábito de fumar (enquanto o tabagismo tem efeito protetor em relação à RCU, está associado a maior risco de desenvolvimento de DC $)^{2,3,6,7}$. Vale ressaltar que atualmente se nota um aumento da incidência da DII em países em desenvolvimento, incluindo o Brasil, o que tem modificado o perfil epidemiológico da doença ${ }^{6}$.

A DC pode acometer qualquer parte do trato gastrointestinal. O processo inflamatório atinge todas as camadas do intestino (inflamação transmural), as úlceras mostram envolvimento segmentar, são descontínuas, tendem a ser profundas, serpiginosas, com áreas de mucosa normal ao redor e aspecto em paralelepípedo (cobblestone). Um marcador histológico é o granuloma epitelioide não caseoso, especialmente quando localizado na lâmina própria. Podem surgir complicações na evolução como estenoses, abscessos e fístulas ${ }^{3}$.

A inflamação da RCU é, em geral, restrita à mucosa e submucosa. Habitualmente começa no reto e se estende em um padrão simétrico e contínuo, envolvendo parte ou a totalidade do cólon. A RCU é classificada de acordo com o segmento envolvido: proctite (apenas reto), colite esquerda (reto, sigmoide e cólon descendente) ou colite extensa (além da flexura esplênica e por todo o cólon - pancolite). Pacientes com pancolite podem, por vezes, apresentar inflamação difusa da porção final do íleo terminal (backwash ileitis) que não deve ser confundida com a ileocolite da DC. O reconhecimento da extensão anatômica da inflamação da mucosa é essencial para a seleção do tratamento e tem implicações prognósticas no curto e longo prazo de acompanhamento ${ }^{2}$.

\section{QUADRO CLÍNICO E DIAGNÓSTICO DA RCU}

Os pacientes com RCU apresentam, caracteristicamente, diarreia com sangue, muco e, eventualmente, pus (diarreia "baixa” ou tipo "colônica" ou disen- 
teria). Outros sintomas como tenesmo, puxo (tenesmo acompanhado de fortes contrações dolorosas da região anal e perianal) e dor abdominal podem estar presentes e, nos casos mais graves, pode haver sinais de resposta inflamatória sistêmica (febre, taquicardia, hipotensão) ${ }^{2}$.

Manifestações extraintestinais podem ocorrer em aproximadamente 25 a $40 \%$ dos indivíduos portadores de DII e incluem artralgia/artrite, aftas orais, eritema nodoso, pioderma gangrenoso, episclerite, uveíte, sacroiliíte, espondilite anquilosante e colangite esclerosante primária (CEP), entre outras. Essas complicações extraintestinais, em $25 \%$ dos casos, podem preceder as manifestações digestivas, o que retarda o diagnóstico. Além disso, podem estar relacionadas ou não à atividade da DII ${ }^{8,9}$. Pacientes com DII também apresentam maior risco de desenvolver fenômenos tromboembólicos ${ }^{10}$.

As manifestações clínicas da RCU dependem da gravidade da doença, habitualmente classificada de acordo com o índice de Truelove e Witts em leve, moderada e grave (Tabela 1$)^{11-13}$.

Tabela 1 Graus de atividade da doença na retocolite ulcerativa

\begin{tabular}{llll} 
Características & Leve & Moderada & Grave \\
$\begin{array}{l}\text { Número de } \\
\text { evacuações/dia }\end{array}$ & $<4$ & 4 a 5 & $\geq 6$ \\
\hline $\begin{array}{lll}\text { Sangue vivo nas fezes } \\
\text { Pouco ou } \\
\text { intermitente }\end{array}$ & Intermitente & Frequente \\
\hline Temperatura $\left({ }^{\circ} \mathrm{C}\right)$ & Normal $(<37,5)$ & Intermediária $(\leq 37,8)$ & $>37,5$ ou $\geq 37,8$ em \\
& & & pelo menos 2 dias de \\
& & & um total de 4 dias \\
\hline Pulso $(b p m)$ & Normal $(<90)$ & $\leq 90$ & $>90$ \\
\hline Hemoglobina $(\mathrm{g} / \mathrm{dL})$ & Normal $>11,5$ & $\geq 10,5$ & $<10,5$ \\
\hline VHS $\left(\mathrm{mm}, 1^{\text {a }} \mathrm{h}\right)$ ou & $\leq 30$ & Intermediária & $>30$ \\
PCR $(\mathrm{mg} / \mathrm{L})$ & Normal & $\leq 30$ & $>30$
\end{tabular}

VHS: velocidade de hemossedimentação; PCR: proteína C-reativa.

Adaptada de Truelove \& Witts"1.

O diagnóstico da DII baseia-se na análise de manifestações clínicas sugestivas, além de exames laboratoriais, radiológicos, endoscópicos e anatomopatológicos compatíveis. Os exames complementares auxiliam no diagnóstico, no estadiamento, no prognóstico, na monitorização da resposta ao tratamento e nas possíveis complicações da DII $^{16,17}$.

No Quadro 1, estão resumidos os principais dados que auxiliam no diagnóstico da DII. 
Quadro 1 Principais dados que auxiliam no diagnóstico da doença inflamatória intestinal (retocolite ulcerativa [RCU] e doença de Crohn [DC])

\section{Laboratório - principais achados}

RCU e DC: anemia ferropriva, elevação das provas de atividade inflamatória como VHS, PCR, alfa-1-glicoproteína ácida, leucocitose e trombocitose; aumento da calprotectina e da lactoferrina nas fezes, deficiência de vitamina B12 (mais comumente na DC ileal).

\section{Endoscopia}

RCU: aspecto contínuo, homogêneo, erosões, apagamento da trama vascular, friabilidade, ulcerações, reto quase sempre comprometido.

DC: aspecto descontínuo (segmentar), áreas adjacentes de aspecto normal, úlceras aftoides, úlceras serpiginosas, profundas, longitudinais, aspecto em "paralelepípedo" ou "cobblestone".

\section{Anatomopatológico}

RCU: mucosa com infiltrado plasmocitário, distorção arquitetural das criptas, atrofia mucosa, criptite, abscessos de cripta; depleção de células caliciformes.

DC: inflamação transmural com infiltrado linfoplasmocitário, irregularidade das criptas, granulomas não caseosos; certa preservação de células caliciformes.

\section{Imagem}

Atualmente, o exame radiológico de escolha para avaliação do intestino delgado e das possiveis complicações da DII é a enterografia, seja por tomografia computadorizada (TC) ou por ressonância magnética (RM). Descrevemos a seguir algumas peculiaridades de cada um deles.

Enterotomografia: consiste na administração de contraste neutro oral associado ao contraste por via intravenosa. O polietilenoglicol e o manitol são os contrastes neutros mais utilizados em nosso meio e permitem a distensão adequada dos segmentos intestinais, pois as avaliações de alças colabadas podem confundir com estenoses ou espessamento, além disso, o contraste neutro aumenta a definição da camada mucosa que seria perdida com o uso de contrastes positivos como o bário. Isso possibilita uma sensibilidade maior que 95\% na detecção da DC, por exemplo. A enterotomografia pode identificar espessamentos segmentares das alças (espessura maior que $5 \mathrm{~mm}$ ), lesões extrínsecas e complicações como trajetos fistulosos e abscessos. Um dos sinais associados à atividade da doença é o aumento da densidade da gordura mesentérica e o ingurgitamento dos vasos mesentéricos, conhecido como "sinal do pente". O estreitamento luminal associado à dilatação a montante indica lesão estenosante. A TC ainda pode ser utilizada para auxiliar procedimentos terapêuticos (p. ex., drenagem de abscessos abdominais). Uma desvantagem significativa da TC é a radiação ionizante, visto que a maioria dos pacientes portadores de Dll é jovem, por vezes necessitando de repetidos exames ao longo da vida, tendo como consequência uma dose cumulativa de radiação.

Enterorressonância: é outro método não invasivo utilizado para quantificar o espessamento mural, graduar a inflamação e determinar a extensão da doença. A RM é superior à TC na documentação, diferenciação de trajetos fistulosos na pelve e na avaliação das complicações perianais da DC. Também é capaz de oferecer imagens estáticas e dinâmicas, não envolve radiação ionizante, tem excelente resolução em partes moles e é segura na gravidez. Pode apresentar um desempenho superior à TC na diferenciação entre o componente fibrótico cicatricial ou atividade inflamatória atual na avaliação das estenoses da DC, o que pode orientar diferentes condutas terapêuticas (p. ex., cirurgia versus tratamento clínico). 


\section{TRATAMENTO DA RCU}

Em uma enfermidade de natureza crônica, com períodos variáveis de atividade e remissão, é fundamental que o médico informe ao paciente sobre o caráter crônico da RCU e a necessidade de acompanhamento periódico, forneça o devido suporte emocional e estimule a boa relação médico-paciente. Para a escolha apropriada da melhor abordagem terapêutica, é necessário considerar o grau de atividade clínica e endoscópica da doença, localização, extensão, eficácia da droga e seus potenciais efeitos colaterais, resposta prévia a algum tipo de tratamento, presença de manifestações extraintestinais ou complicações relacionadas à doença ${ }^{2,3}$.

Atualmente, os objetivos do tratamento não são apenas o controle dos sintomas, mas, principalmente, o controle sustentado da inflamação, por meio da cicatrização da mucosa e prevenção de lesões estruturais irreversíveis e complicações que, por sua vez, levam à hospitalização e à cirurgia ${ }^{15,16}$.

\section{Abordagem terapêutica na RCU}

Antidiarreicos, antiespasmódicos e opioides não devem ser usados de rotina pelo risco de desenvolvimento de megacólon tóxico. A diarreia sanguinolenta pode gerar desidratação, anemia e distúrbios hidreletrolíticos, desequilíbrios que devem ser devidamente corrigidos. Atenção especial deve ser dada à condição nutricional do paciente. Embora não haja dúvida de que antibióticos sejam úteis em certas situações capazes de complicar a DII, como fístulas, abscessos, sepse, infecções em geral e megacólon tóxico, seu uso como tratamento primário ou adjunto na DC ou na RCU não complicada é controvertido. Os estudos com antibióticos são, em geral, não controlados e com pequeno número de pacientes, o que impede conclusões mais definitivas. Além disso, convém lembrar a preocupação com a infecção pelo Clostridium difficile, muito comum nesses pacientes ${ }^{17,18}$.

O tratamento medicamentoso da RCU obedece ao esquema tradicional denominado step-up (de baixo para cima), uma designação que corresponde ao uso inicial de medicamentos com baixo potencial para efeitos colaterais e, na medida em que a doença exigir, progride-se para alternativas mais potentes do ponto de vista anti-inflamatório, porém, com potencial maior de efeitos colaterais $^{17,19}$.

Assim, em pacientes com RCU leve/moderada, recomenda-se inicialmente o uso de derivados salicílicos por via oral. Nesse grupo de medicamentos são incluídas a tradicional sulfassalazina (SSZ) e a mesalazina (sulfassalazina, 2 a 4 g/dia e mesalazina, 2 a 4 g/dia, dose máxima de 4,8 g/dia). 
Quando ingerida, a SSZ é desdobrada, no cólon, por ação bacteriana, em sulfapiridina (grandemente absorvida) e ácido 5-aminossalicílico (5-ASA ou mesalazina ou mesalamina), que é pouco absorvido. A mesalazina é o princípio ativo do medicamento, agindo de forma tópica. Entre os vários mecanismos de ação do 5-ASA, estão a inibição da produção de leucotrienos e a capacidade de assimilação de radicais livres ${ }^{20}$. A mesalazina também pode ser empregada na forma de enema ou supositórios, 1 a $4 \mathrm{~g} /$ dia. A associação com tratamento tópico (enema de mesalazina) parece favorecer a resposta terapêutica. Caso o paciente não responda a esse tratamento (em geral após 2 a 4 semanas), os corticosteroides devem ser acrescentados (p. ex., prednisona oral, 0,75 a $1 \mathrm{mg} / \mathrm{kg} / \mathrm{dia}$, sem necessidade de ultrapassar $60 \mathrm{mg} / \mathrm{dia}$ ) e retirados paulatinamente (cerca de 5 a $10 \mathrm{mg} /$ semana), tão logo o paciente apresente boa resposta clínica (em geral entre 2 e 4 semanas). Os derivados salicílicos (sulfassalazina ou mesalazina em doses, em geral, entre 2 e $3 \mathrm{~g} / \mathrm{dia}$ ) devem ser mantidos indefinidamente para reduzir a chance de recaídas. $\mathrm{O}$ controle da inflamação da mucosa, independentemente da terapia utilizada (p. ex., derivados salicílicos, tiopurinas), é fundamental para a prevenção do câncer colorretal tanto na RCU quanto na DC colônica ${ }^{21}$. Como a sulfassalazina interfere na absorção de ácido fólico, com consequente anemia macrocítica, o ácido fólico deve ser suplementado concomitantemente (2 a $5 \mathrm{mg}, 2$ a 3 vezes por semana, via oral). A dosagem maior de mesalazina por comprimido ou por sachê configura uma interessante alternativa para os pacientes com DII em uso de salicilatos, pois pode aumentar a adesão ao tratamento ${ }^{17,20,22}$. Nos pacientes portadores de doença distal (proctite ou proctossigmoidite), pode-se utilizar inicialmente apenas terapia tópica, via retal, diária (supositório de mesalazina 0,5 a $1 \mathrm{~g}$ /dia no caso de proctite ou enema de mesalazina 1 a $4 \mathrm{~g} /$ dia na proctossigmoidite) e, na fase de manutenção, cerca de 3 vezes/semana ${ }^{17,22}$.

Os pacientes dependentes de corticosteroide (pacientes que requerem doses, ainda que baixas, de corticosteroide para se manterem oligo ou assintomáticos) e os refratários ao corticosteroide (pacientes que não respondem após cerca de 4 semanas de tratamento com corticosteroide em dose adequada) devem iniciar uso de imunossupressor oral, azatioprina (AZA, 2 a $3 \mathrm{mg} / \mathrm{kg} / \mathrm{dia}$ ) ou 6-mercaptopurina (6-MP, 1 a 1,5 mg/kg/dia). Sugere-se iniciar com $50 \mathrm{mg} /$ dia de AZA ou 6-MP e, a seguir, dependendo dos exames laboratoriais realizados a cada 10 a 14 dias (hemograma, transaminases, amilase), evoluir para a dose ideal. Os efeitos colaterais da AZA e 6-MP ocorrem em aproximadamente 10 a $15 \%$ dos casos e podem ser de natureza alérgica: febre, rash cutâneo, mal-estar, náuseas, vômitos, dor abdominal, diarreia, hepatite e pancreatite; e não alérgica: depressão medular (leucopenia, trombocitopenia, anemia) e alte- 
rações de enzimas hepáticas. Além disso, aumentam o risco de infecções e de algumas neoplasias, principalmente linfoma e câncer de pele não melanoma. Pacientes não responsivos aos imunossupressores são candidatos à terapia com biológicos (p. ex., antifator de necrose tumoral - anti-TNF, como é o caso do infliximabe, adalimumabe e golimumabe $)^{17,19,22}$. Em casos com dependência do corticosteroide, porém, com intensa atividade endoscópica, pode-se optar pela indicação direta de anti-TNF ${ }^{23}$.

A RCU grave, que corresponde a cerca de $20 \%$ de todos os casos de RCU, é definida como seis ou mais evacuações com sangue por dia, associadas a pelo menos uma das seguintes manifestações: a) taquicardia (> $90 \mathrm{bpm}$ ); b) febre $\left(\mathrm{T}>37,8^{\circ} \mathrm{C}\right)$; c) anemia $(\mathrm{Hb}<10,5 \mathrm{~g} / \mathrm{dL})$; d) VHS $>30 \mathrm{~mm}, 1^{\text {a }}$ h ou PCR $>30$ $\mathrm{mg} / \mathrm{L}$ (Tabela 1) 2,12,13,17. A chamada colite "fulminante" é assim denominada quando há mais de dez evacuações/dia, sangramento contínuo (enterorragia), toxicidade sistêmica (febre, taquicardia, anemia, leucocitose), VHS e PCR elevadas e necessidade de transfusão de sangue ${ }^{12,17}$. Mais recentemente, o termo fulminante, embora consagrado, tem sido alvo de críticas. A colite fulminante foi definida nos anos 1950 e se referia a um único ataque de colite com evolução para a morte em um período de 12 meses. A colite fulminante foi, portanto, definida em uma época de menos recursos terapêuticos e de infraestrutura hospitalar. Hoje, prefere-se manter a terminologia RCU grave (colite grave ou colite grave aguda). Entretanto, é óbvio que dentro do espectro da RCU grave haverá aqueles casos que classificarão o paciente em uma posição de maior risco de morte ${ }^{13}$.

O megacólon tóxico corresponde à dilatação colônica não obstrutiva ( $\geq$ $5,5 \mathrm{~cm}$ ), total ou segmentar (geralmente cólon transverso), associada a toxicidade sistêmica ${ }^{12,17}$. Redução do nível sérico de potássio e magnésio, consumo de antidiarreicos, anticolinérgicos e narcóticos são fatores de risco para o megacólon tóxico ${ }^{2,12,17}$. Estima-se que 5\% dos casos de RCU grave internados podem complicar com megacólon tóxico ${ }^{17}$. Perfuração é a complicação mais temida diante desses casos graves de RCU, com mortalidade próxima de $50 \%{ }^{17}$. Outras situações graves relacionadas à RCU incluem a hemorragia e o tromboembolismo ${ }^{2,10,13,17}$.

Os pacientes portadores de RCU grave devem ser prontamente internados. As medidas gerais são fundamentais no tratamento e têm o potencial de prevenir complicações ${ }^{12,17}$. Incluem a reposição hidreletrolítica, com cuidado especial para a reposição de potássio e magnésio. Caso seja possível, retossigmoidoscopia é recomendável, sem preparo, sem inflar ar, para coleta de biópsias e pesquisa de inclusões de citomegalovírus. Coproculturas e pesquisa de toxinas A e B do Clostridium difficile estão indicadas. Heparina subcutânea profilática reduz o risco de tromboembolismo. O suporte nutri- 
cional (enteral ou, excepcionalmente, parenteral) é medida recomendada nos casos com desnutrição ou no preparo para cirurgia. Deve-se evitar o uso de anticolinérgicos, antidiarreicos, opioides, narcóticos e anti-inflamatórios não esteroides (AINE) ${ }^{12,17}$. Caso o paciente tolere, enemas de mesalazina podem ser utilizados. Os antibióticos (p. ex., ciprofloxacina + metronidazol) estão indicados no caso de infecções confirmadas ou suspeitas. Transfusão de sangue é habitualmente prescrita quando a $\mathrm{Hb}$ atinge níveis inferiores a $8 \mathrm{~g} / \mathrm{dL}$. O acompanhamento conjunto envolvendo o gastroenterologista e o coloproctologista é fundamental nos casos de RCU grave e megacólon tóxico ${ }^{12,17}$.

Os corticosteroides por via intravenosa são a primeira opção de tratamento na RCU grave. Hidrocortisona, $100 \mathrm{mg}$ a cada 6 a 8 horas, ou prednisolona, $60 \mathrm{mg} /$ dia, são os mais empregados. A não resposta ao tratamento com corticosteroide após 3 a 7 dias, e caso não haja indicação cirúrgica, implica terapia de resgate com ciclosporina ou infliximabe ${ }^{2,17}$. Embora tacrolimus possa ser utilizado como medida de resgate, sua eficácia ainda precisa ser mais bem esclarecida por meio de estudos controlados ${ }^{2,12,17}$.

A ciclosporina gera resposta favorável inicial em aproximadamente $80 \%$ dos casos. A dose de $2 \mathrm{mg} / \mathrm{kg} / \mathrm{dia}$, sob infusão intravenosa contínua, equivale à de $4 \mathrm{mg} / \mathrm{kg} / \mathrm{dia}^{17}$. Monitoração dos níveis séricos de ciclosporina é necessária (150 a $250 \mathrm{ng} / \mathrm{mL}$ no caso do uso de $2 \mathrm{mg} / \mathrm{kg}$ e 250 a $450 \mathrm{ng} / \mathrm{mL}$ no caso de $4 \mathrm{mg} / \mathrm{kg})^{2,12,17}$. Os resultados no longo prazo, no entanto, são ruins. Em 7 anos de acompanhamento, mais de $80 \%$ dos pacientes foram operados ${ }^{24}$. $\mathrm{O}$ uso prévio de azatioprina acarreta menor grau de resposta à ciclosporina ${ }^{24}$. Por outro lado, a associação com azatioprina, na forma de manutenção, após remissão com ciclosporina, reduz em 40 a 50\% a taxa de colectomia ${ }^{12,17}$. Seu uso não se associa a complicações pós-operatórias ${ }^{12,17}$. Os efeitos colaterais (em até 18\%) são importantes, como nefropatia, hipertensão, hipertrofia gengival, infecções, tremores, hipertricose, elevação de transaminases, parestesia, anafilaxia, entre outros ${ }^{24}$. Profilaxia do Pneumocystis jirovecii com sulfametoxazol/trimetoprim é recomendável no período em que o paciente estará com tríplice imunossupressão (corticosteroide oral [desmame], azatioprina [2 a 3 $\mathrm{mg} / \mathrm{kg}$ ] ou 6-mercaptopurina [ 1 a $1,5 \mathrm{mg} / \mathrm{kg}$ ] e ciclosporina oral [5 a $10 \mathrm{mg} /$ $\mathrm{kg}$, com concentração sérica da ordem de 200 a $400 \mathrm{ng} / \mathrm{mL}$ ), após a fase de ciclosporina intravenosa $\mathrm{a}^{2,12,17}$.

Infliximabe (anti-TNF) na RCU (5 mg/kg, semanas 0, 2 e 6 e, a seguir, a cada 8 semanas) gerou resultados semelhantes aos obtidos com a ciclosporina no curto prazo $^{25}$. No longo prazo, a taxa de colectomia foi de $50 \%$ em 3 a 5 anos de acompanhamento, valores comparáveis aos observados com ciclosporina $^{25,26}$. Os resultados são melhores com maior número de infusões ${ }^{17,27}$. O 
benefício do infliximabe não parece ser afetado pelo uso prévio de azatioprina ${ }^{17,25-27}$. Pacientes com colite fulminante não respondem tão bem ao infliximabe ${ }^{24-27}$. Discute-se, no caso da RCU grave, se a dose de infliximabe deveria ser maior, em virtude da perda colônica (exsudação) de proteínas, incluindo o próprio anti-TNF ${ }^{17}$. Neste caso, doses mais elevadas deveriam ser fornecidas ao paciente. A associação com azatioprina, possivelmente, gera melhores resultados $^{2,17,25-27}$. Aparentemente, não há necessidade de profilaxia do $P$. jirovecii ${ }^{27}$. Alguns trabalhos mostram maior risco de complicações pós-operatórias em usuários de infliximabe $e^{2,17}$.

Estudo prospectivo, randomizado, comparando infliximabe com ciclosporina, revelou que ambas as drogas são igualmente eficazes na RCU grave, com resposta clínica no $7^{\circ}$ dia, taxa de colectomia em 3 meses e frequência de efeitos colaterais semelhantes ${ }^{27}$. No entanto, um estudo retrospectivo mostrou melhores resultados com o uso de infliximabe quando comparado com a ciclosporina ${ }^{28}$. Diferenças metodológicas e seleção de pacientes, entre outros aspectos, podem explicar esses resultados tão díspares. Por outro lado, uma metanálise confirmou resposta semelhante com infliximabe e ciclosporina quando usadas como terapia de resgate na $\mathrm{RCU}^{29}$.

Portanto, no momento, ambas as drogas são factíveis em casos graves de RCU, ficando a escolha na dependência da experiência do centro e do profissional, além da avaliação e caracterização do paciente $\mathrm{e}^{17,19,30}$.

\section{Imunobiológicos e pequenas moléculas para uso oral na DII}

A inclusão dos biológicos no arsenal terapêutico da DII, com sua capacidade de promover cicatrização da mucosa, tem modificado a história natural da doença com tendência à diminuição de cirurgias e/ou hospitalizações, pelo menos no curto e médio prazo (1 a 5 anos de acompanhamento $)^{31,32}$.

Infliximabe (IFX) foi o primeiro biológico a ser usado na DC. Trata-se de anticorpo quimérico monoclonal anti-TNF cujo primeiro estudo publicado (cA2) foi em 1997. Este anticorpo apresenta 75\% de sua proteína de origem hunana e os $25 \%$ restantes de origem animal (murínica) ${ }^{33}$. A partir daí vários estudos demonstraram sua eficácia no tratamento da DII, tanto na fase aguda quanto na manutenção da remissão, o que motivou seu uso nos casos mais graves de DII. A droga foi liberada em 2000 no Brasil para o tratamento da DC e em 2006 para o da RCU. O IFX liga-se com alta afinidade ao TNF-alfa e bloqueia a interação citocina-receptor, neutralizando a sua intensa atividade pró-inflamatória. O IFX (Remicade ${ }^{\circledast}$ ) é um pó liofilizado que, após reconstituição com $10 \mathrm{~mL}$ de água destilada, deve ser administrado por via intravenosa nas semanas 0, 2 e 6 (esquema de indução) e, a seguir, a cada 8 
semanas (esquema de manutenção). A dose é inicialmente de $5 \mathrm{mg} / \mathrm{kg}$. O tempo de tratamento é indeterminado, e ainda não há nenhum consenso sobre quando suspender. Nos casos de pacientes que apresentam resposta incompleta durante o tratamento de manutenção (não respondedores secundários), pode-se ajustar a dose para $10 \mathrm{mg} / \mathrm{kg}$ ou diminuir o intervalo das doses para cada 4 semanas. A avaliação dos níveis séricos do anti-TNF e de seu respectivo anticorpo, ainda não disponível no Brasil, certamente facilitará nossas decisões quanto à conduta mais adequada a tomar diante da perda de resposta aos biológicos, inclusive com vantagens do ponto de vista de custo ${ }^{34}$. As reações adversas mais comuns são infecções, reações relacionadas à infusão, cefaleia e dor abdominal. A anafilaxia pode ter espectro variável desde sintomas leves que são tratados com anti-histamínicos e corticosteroides e não contraindicam o uso posterior até sintomas graves os quais motivam a parada da infusão e suspensão do tratamento com este fármaco. Um biossimilar do infliximabe (Remsima ${ }^{\circledR}$ ) foi recentemente aprovado no Brasil tanto para a RCU quanto para a DC.

Em 2006, surgiu a publicação de um segundo anti-TNF para o tratamento da DII denominado adalimumabe (ADA) ${ }^{35}$. Este agente biológico anti-TNF, totalmente humano, foi liberado no Brasil em 2007 para o tratamento da DC em adultos e, recentemente, a droga foi aprovada para o tratamento da $\mathrm{RCU}^{36}$. O ADA (Humira ${ }^{\circledR}$ ) é um anticorpo anti-TNF totalmente humano de utilização subcutânea. É apresentado em seringas contendo $0,8 \mathrm{~mL}$ da solução e $40 \mathrm{mg}$ de anticorpo. A dose é fixa de $40 \mathrm{mg}$ a cada 2 semanas. O esquema de indução consiste na administração de $160 \mathrm{mg}$ na semana 0 , seguida de $80 \mathrm{mg}$ após 2 semanas e, a partir daí, $40 \mathrm{mg}$ a cada 2 semanas por tempo indeterminado. Diante da perda de resposta à droga, também pode ser otimizada reduzindo-se o intervalo entre as aplicações para 1 semana ${ }^{37}$. Os efeitos colaterais mais comuns são: infecções, reações no sítio da injeção, cefaleia e rash.

O certolizumabe pegol (CZB) $\left(\mathrm{Cimzia}^{\circledR}\right)$, um anti-TNF humanizado e peguilado, também se mostrou eficaz no tratamento da DC ativa e em remissão (manutenção) ${ }^{38,39}$. A droga não foi testada na RCU. É utilizado na dose de 400 mg (2 ampolas), por via subcutânea, nas semanas 0, 2 e 4 (indução) e, a seguir, a cada 4 semanas (manutenção). CZB, ao contrário dos demais anti-TNF, contém apenas uma região $\mathrm{Fab}$ da imunoglobulina a qual é envolvida por duas cadeias de polietilenoglicol. Não contém a porção Fc da imunoglobulina (deste modo, não se liga ao receptor $\mathrm{FcRn}$ ), o que lhe confere algumas características como: não induz a ativação de complemento, não induz a citotoxicidade dependente de anticorpo e nem a apoptose celular e também não atravessa de forma ativa a barreira placentária ${ }^{38,39}$. Dentre as reações adversas, as infecções, 
embora infrequentes, são as mais comuns ${ }^{38,39}$. Golimumabe, outro agente anti-TNF de natureza humana, eficaz no tratamento da RCU, ainda não foi liberado para o tratamento da DII no Brasil².

$\mathrm{O}$ vedolizumabe (VDZ) (Entyvio ${ }^{\circledR}$ ) foi o biológico mais recentemente aprovado no Brasil para o tratamento da DII (RCU e DC). Trata-se de um anticorpo monoclonal humanizado que seletivamente reconhece a integrina a4b7 na superfície dos linfócitos, impedindo a interação a4b7/MAdCAM-1 no tecido intestinal (reduz a diapedese de linfócitos para o tecido intestinal e, consequentemente, a inflamação $)^{40-43}$. Desta maneira, o VDZ tem mecanismo de ação diferente dos demais já citados. A eficácia na indução e manutenção da remissão na RCU e na DC foi constatada nos estudos GEMINI ${ }^{41}$ e com bom perfil de segurança ${ }^{42}$. A dose é fixa de $300 \mathrm{mg}$ IV. A indução é realizada nas semanas 0,2 e 6 e, a seguir, a manutenção é feita com infusão intravenosa a cada 8 semanas. A possibilidade de otimização para cada 4 semanas é possível ${ }^{40-43}$.

Os biológicos são, no momento, as drogas de escolha para os casos mais graves e refratários de DII. No tratamento da RCU, os únicos biológicos liberados até o momento no Brasil são o infliximabe e seu biossimilar, o adalimumabe e o vedolizumabe ${ }^{36,41,44}$. Eles são reservados para as formas corticosteroide-dependentes e naquelas refratárias aos corticosteroides, imunossupressores e aminossalicilatos ${ }^{36,41,44}$. Também, como mencionado anteriormente, infliximabe pode ser utilizado como terapia de resgate nos pacientes com RCU grave não responsiva a 3 dias de corticosteroide intravenoso ${ }^{27}$.

Vale ressaltar algumas situações que configuram contraindicação para o uso de biológicos. Dentre elas, citam-se: infecções ativas, abscessos abdominais e perianais, tuberculose ativa, alergia ou hipersensibilidade aos componentes da droga, esclerose múltipla, neurite óptica e insuficiência cardíaca grave $^{2,3}$.

Como parte da avaliação pré-terapia com biológicos deve ser feito screening com radiografia do tórax e PPD para descartar tuberculose ativa e/ou latente (em caso de paciente assintomático, com radiografia de tórax normal, porém, com PPD $\geq 5 \mathrm{~mm}$, iniciar isoniazida, $300 \mathrm{mg} / \mathrm{dia}$, via oral, e só começar o biológico a partir de 1 mês da profilaxia, que deverá, por sua vez, ser mantida por 6 meses), sorologias virais para hepatite B e HIV, além de atualização vacinal e recomendação de algumas vacinas, como antipneumocócica, antimeningocócica e anti-influenza $(\mathrm{H} 1 \mathrm{~N} 1)^{45,46}$.

Outro agente biológico, com mecanismo de ação diferente dos anti-TNF e que deverá ser liberado no Brasil em breve, é o ustequinumabe (já liberado para uso na DC na Europa e nos Estados Unidos). Trata-se de um anticorpo monoclonal humano que bloqueia a atividade de IL-12 e IL-23 por meio da 
inibição de sua subunidade p40 e, consequentemente, reduz a ativação da resposta Th1 e Th17 de elevada importância na patogênese da $\mathrm{DC}^{47}$. Os dados de ensaios controlados randomizados e estudos observacionais do mundo real demonstram que este novo agente é clinicamente eficaz e razoavelmente seguro para o tratamento de pacientes com DC moderada a grave, com um número significativo de dados de segurança também relatados em estudos em pacientes com psoríase e esclerose múltipla ${ }^{47,48}$.

Ustequinumabe é uma opção de tratamento atraente para pacientes com resposta inadequada ou com perda de resposta, intolerância ou contraindicação médica ao tratamento com antagonistas do TNF. No entanto, também pode ser utilizado como um biológico de primeira linha em pacientes que falharam à terapia convencional. Maiores evidências são necessárias para determinar como este novo medicamento promissor será posicionado em algoritmos de tratamento da DC, além do seu custo-benefício ${ }^{48}$.

Ainda nesta mesma linha de bloqueio da vertente IL-12/IL-23, um inibidor da subunidade p19 da IL-23 (que bloqueia seletivamente a IL-23, sem impacto sobre a IL-12), o MEDI 2070 ou brazikumabe, foi testado recentemente na DC com resultados favoráveis (fase 2), particularmente naqueles pacientes que previamente ao tratamento apresentavam elevação sérica de IL-22. Esse fato descortina uma nova fase no tratamento da DII, uma fase em que se podem antever os resultados com os biológicos ${ }^{49}$.

Finalmente, configuram interessantes perspectivas as chamadas pequenas moléculas para uso oral no tratamento da $\mathrm{DII}^{49,50}$. Neste grupo incluem-se, entre outros, o tofacitinibe na RCU (inibidor de quinases intracelulares, a saber, JAK 1, JAK 2 e JAK 3), o ozanimode na RCU e DC (inibidor do receptor de esfingosina-1-fosfato na superfície dos linfócitos impedindo sua saída do gânglio linfático), o laquinimode na DC (direcionamento da reação imunológica para um perfil Th2) e o mongersen na DC (inibidor de SMAD7 intracelular com restauração do poder inibitório do TGF- $\beta 1)^{49,50}$. Esses medicamentos, na sua maioria, encontram-se em fase 2 ou 3 de investigação. Desses, o tofacitinibe provavelmente deverá ser o primeiro aprovado no Brasil para uso na RCU.

As pequenas moléculas diferem dos biológicos por serem de uso oral, agirem de forma intracelular, terem meia-vida mais curta e ausência de imunogenicidade e gerarem genéricos em vez de biossimilares. Espera-se também que sejam mais baratos que os biológicos ${ }^{50}$.

Na Tabela 2, estão listados os principais biológicos e pequenas moléculas para uso oral já comercializados ou ainda em estudo na DII. Notar que vários mecanismos de ação entram em jogo no combate à inflamação ${ }^{49,50}$. 
Tabela 2 Principais agentes biológicos e pequenas moléculas para administração oral em uso ou ainda testados na doença inflamatória intestinal e seus respectivos mecanismos de ação

\begin{tabular}{ll}
$\begin{array}{l}\text { Biológico ou pequena } \\
\text { molécula }\end{array}$ & Mecanismo de ação \\
Infliximabe & Inibição do fator de necrose tumoral (anti-TNF- $\alpha$ ) \\
$\begin{array}{l}\text { Adalimumabe } \\
\text { Certolizumabe } \\
\text { Golimumabe }\end{array}$ & \\
\hline Vedolizumabe & Inibidor da integrina $\alpha 4 \beta 7$ \\
\hline Etrolizumabe & Inibidor da integrina $\beta 7$ \\
\hline PF-00547659 & Inibidor da molécula de adesão (MAdCam-1) do endotélio \\
\hline Ustequinumabe & Bloqueio da via IL-12/IL-23 (via p40) \\
\hline MEDI 2070 & Bloqueio seletivo de IL-23 (via p19) \\
\hline Tofacitinibe & Inibição de quinases intracelulares (JAK1, JAK2, JAK3) \\
\hline Mongersen & Inibição do SMAD7 \\
\hline Ozanimode & Inibidor do receptor da esfingosina-1-fosfato (S1P1) \\
\hline Laquinimode & Direcionamento das células T para perfil Th2 \\
\hline
\end{tabular}

\section{REFERÊNCIAS BIBLIOGRÁFICAS}

1. Kirsner JB. Historical aspects of inflammatory bowel disease. J Clin Gastroenterol. 1988;10:286-97.

2. Ordás I, Eckmann L, Talamini M, et al. Ulcerative colitis. Lancet. 2012;380:1606-19.

3. Baumgart DC, Sandborn WJ. Crohn's disease. Lancet. 2012;380:1590-605.

4. Sartor RB. Current concepts of the etiology and pathogenesis of ulcerative colitis and Crohn's disease. Gastroenterol Clin North Am. 1995;24:475-507.

5. Bouma G, Strober W. The immunological and genetic basis of inflammatory bowel disease. Nat Rev Immunol. 2003;3:521-33.

6. Loftus EV Jr., Sandborn WJ. Epidemiology of inflammatory bowel disease. Gastroenterol Clin North Am. 2002;31:1-20.

7. Mahid SS, Minor KS, Soto RE, et al. Smoking and inflammatory bowel disease: a meta-analysis. Mayo Clin Proc. 2006;81:1462-71.

8. Ott C, Schölmerich J. Extraintestinal manifestations and complications in IBD. Nat Rev Gasroenterol Hepatol. 2013;10:585-95.

9. Levine JS, Burakoff R. Extraintestinal manifestations of inflammatory bowel disease. Gastroenterol Hepatol. 2011;7:235-41.

10. Scoville, et al. Venous thromboembolism in patients with inflammatory bowel diseases: a case-control study of risk factors. Inflamm Bowel Dis. 2014;20:631-6.

11. Truelove SC, Witts LJ. Cortisone in ulcerative colitis; final report on a therapeutic trial. Br Med J. 1955;2:1041-8.

12. Kornbluth A, Sachar DB. Ulcerative colitis practice guidelines in adults: American College of Gastroenterology, Practice Parameters Committee. Am J Gastroenterol. 2010;105:501-23.

13. Magro F, Gionchetti P, Eliakim R, et al. Third european evidence-based consensus on diagnosis and management of ulcerative colitis. Part 1: Definitions, diagnosis, extra-intestinal manifesta- 
tions, pregnancy, cancer surveillance, surgery, and ileo-anal pouch disorders. J Crohns Colitis. 2017;11(6):649-70.

14. Gomollón F, Dignass A, Annese V, et al. $3^{\text {rd }}$ European evidence-based consensus on the diagnosis and management of Crohn's disease 2016. Part 1: Diagnosis and medical management. J Crohns Colitis. 2017;11(1):3-25.

15. Sandborn WJ, Hanauer S, Van Assche G, et al. Treating beyond symptoms with a view to improving patient outcomes in inflammatory bowel diseases. J Crohn's Colitis. 2014;8:927-35.

16. Flynn A, Kane S. Mucosal healing in Crohn's disease and ulcerative colitis: what does it tell us? Curr Opin Gastroenterol. 2011;27:342-5.

17. Harbord M, Eliakim R, Bettenworth D, et al. Third european evidence-based consensus on diagnosis and management of ulcerative colitis. Part 2: Current management. J Crohns Colitis. 2017;11:769-84.

18. Keohane J, Shanahan F. Therapeutic manipulation of the microbiota in inflammatory bowel disease: antibiotics and probiotics. In: Targan SR, Shanahan F, Karp LC (eds.). Inflammatory bowel disease: translating basic science into clinical practice. London: Wiley-Blackwell; 2010.

19. Brazilian Study Group of Inflammatory Bowel Diseases. Consensus guidelines for the management of inflammatory bowel disease. Arq Gastroenterol. 2010;47:313-25.

20. Ford AC, Achkar JP, Khan KJ, et al. Efficacy of 5-aminosalicylates in ulcerative colitis: systematic review and meta-analysis. Am J Gastroenterol. 2011;106:601-16.

21. Van Schaik FDM, van Oijen MGH, Smeets HM, et al. Thiopurines prevent advanced colorectal neoplasia in patients with inflammatory bowel disease. Gut. 2012;61:235-40.

22. Burger D, Travis S. Conventional medical management of inflammatory bowel disease. Gastroenterology. 2011;140:1827-37.

23. Bressler B, Marshall JK, Bernstein CN, et al. Clinical practice guidelines for the management of nonhospitalized ulcerative colitis: the Toronto Consensus. Gastroenterology. 2015;148:1035-58.

24. Moskovitz DN, Van Assche G, Maenhout B, et al. Incidence of colectomy during long-term follow-up after cyclosporine-induced remission of severe ulcerative colitis. Clin Gastroenterol Hepatol. 2006;4:760-5.

25. Järnerot G, Hertervig E, Friis-Liby I, et al. Infliximab as rescue therapy in severe to mederately severe ulcerative colitis: a randomized, placebo-controlled study. Gastroenterology. 2005;128:1805-11.

26. Gustavsson A, Järnerot G, Hertervig E, et al. Clinical trial: colectomy after rescue therapy in ulcerative colitis - 3-year follow-up of the Swedish-Danish controlled infliximab study. Aliment Pharmacol Ther. 2010;32:984-9.

27. Laharie D, Bourreille A, Branche J, et al. Ciclosporin versus infliximab in patients with severe ulcerative colitis refractory to intravenous steroids: a parallel, open-label randomised controlled trial. Lancet. 2012;380:1909-15.

28. Croft A, Walsh A, Doecke J, et al. Outcomes of salvage therapy for steroid-refractory acute severe ulcerative colitis: ciclosporin vs. infliximab. Aliment Pharmacol Ther. 2013;38:294-302.

29. Chang KH, Burke JP, Coffey JC. Infliximab versus cyclosporin as rescue therapy in acute severe steroid-refractory ulcerative colitis: a systematic review and metanalysis. Int J Colorectal Dis. 2013;28:287-93.

30. Ho GT, Mowat C, Goddard CJ, et al. Predicting the outcome of severe ulcerative colitis: development of a novel risk score to aid early selection of patients for second-line medical therapy or surgery. Aliment Pharmacol Ther. 2004;19:1079-87.

31. Schnitzler F, Fidder H, Ferrante M, et al. Mucosal healing predicts long-term outcome of maintenance therapy with infliximab in Crohn's disease. Inflamm Bowel Dis. 2009;15:1295-301.

32. Ferrante M, Colombel JF, Sandborn WJ, et al. Validation of endoscopic activity scores in patients with Crohn's disease based on a post hoc analysis of data from SONIC. Gastroenterology. 2013;145:978-86. 
33. Targan SR, Hanauer SB, Van Deventer SJ, et al. A short-term stydy of chimeric monoclonal antibody cA2 to tumor necrosis factor alpha for Crohn's disease. Crohn's disease cA2 Study Group. N Engl J Med. 1997;337:1029-35.

34. Steenholdt C, Brynskov J, Thomsen O, et al. Individualised therapy is more cost-effective than dose intensification in patients with Crohn's disease who lose response to anti-TNF treatment: a randomised, controlled trial. Gut. 2014;63:919-27.

35. Hanauer SB, Sandborn WJ, Rutgeerts P, Fedorak RN, Lukas N, Macintosh D, et al. Human anti-tumor necrosis fator monoclonal antibody (adalimumab) in Crohn's disease: The Classic-I trial. Gastroenterology. 2006;130:323-33.

36. Sandborn WJ, Van Assche G, Reinisch W, et al. Adalimumab induces and maintains clinical remission in patients with moderate-to-severe ulcerative colitis. Gastroenterology. 2012;142:257-65.

37. Wolf D, D' Haens G, Sandborn WJ, et al. Escalation to weekly dosing recaptures response in adalimumab-treated patients with moderately to severe active ulcerative colitis. Aliment Pharmacol Ther. 2014;40:486-97.

38. Schreiber S. Certolizumab pegol for the treatment of Crohn's disease. Ther Adv Gastroenterol. 2011;4:375-89.

39. Sandborn WJ, Lee SD, Randall C, et al. Long-term safety and efficacy of certolizumab pegol in the treatment of Crohn's disease: 7-year results from the PRECiSE 3 study. Aliment Pharmacol Ther. 2014;40:903-16.

40. Soler-Ferran D, Briskin MJ. Integrin $\alpha 4 \beta 7$ antagonists: activities, mechanisms of action and therapeutic prospects. Curr Immunol Rev. 2012;8:118-34.

41. Bryant RV, Sandborn WJ, Travis SPL. Introducing vedolizumab to clinical practice: who, when, and how? J Crohn's Colitis. 2015;9:356-66.

42. Colombel J-F, Sands BE, Rutgeerts P, et al. The safety of vedolizumab for ulcerative colitis and Crohn's disease. Gut. 2017;66:839-51.

43. Krupka N, Baumgart DC. Designing biologic selectivity for inflammatory bowel disease - role of vedolizumab. Drug Design Dev Ther. 2015;9:147-54.

44. Rutgeerts P, Sandborn WJ, Feagan BG, et al. Infiliximab for induction and maintenance therapy for ulcerative colitis. N Engl J Med. 2005;353:2462-76.

45. Mangini C, Fiuza de Melo, FA. Artrite reumatóide, terapia imunossupressora e tuberculose. Rev Bras Reumatol. 2003;43:XI-XV.

46. Chebli JMF, Gaburri PD, Chebli LA, et al. A guide to preparation of patients with inflammatory bowel diseases for anti-TNF- $\alpha$ therapy. Med Sci Monit. 2014;20:487-98.

47. Feagan BG, Sandborn WJ, Gasink C, et al. Ustekinumab as induction and maintenance therapy for Crohn's disease. N Engl J Med. 2016;375:1946-96.

48. Danese S, Bonovas S, Peyrin-Biroulet L. Positioning ustekinumab in Crohn's disease: from clinical evidence to clinical practice. J Crohns Colitis. 2017.

49. Coskun M, Vermeire S, Nielsen $\mathrm{OH}$. Novel targeted therapies for inflammatory bowel disease. Trends Pharmacol Sci. 2017;38:127-42.

50. Olivera M, Danese S, Peurin Biroulet L. Next generation of small molecules in inflammatory bowel disease. Gut. 2017;66:199-209. 